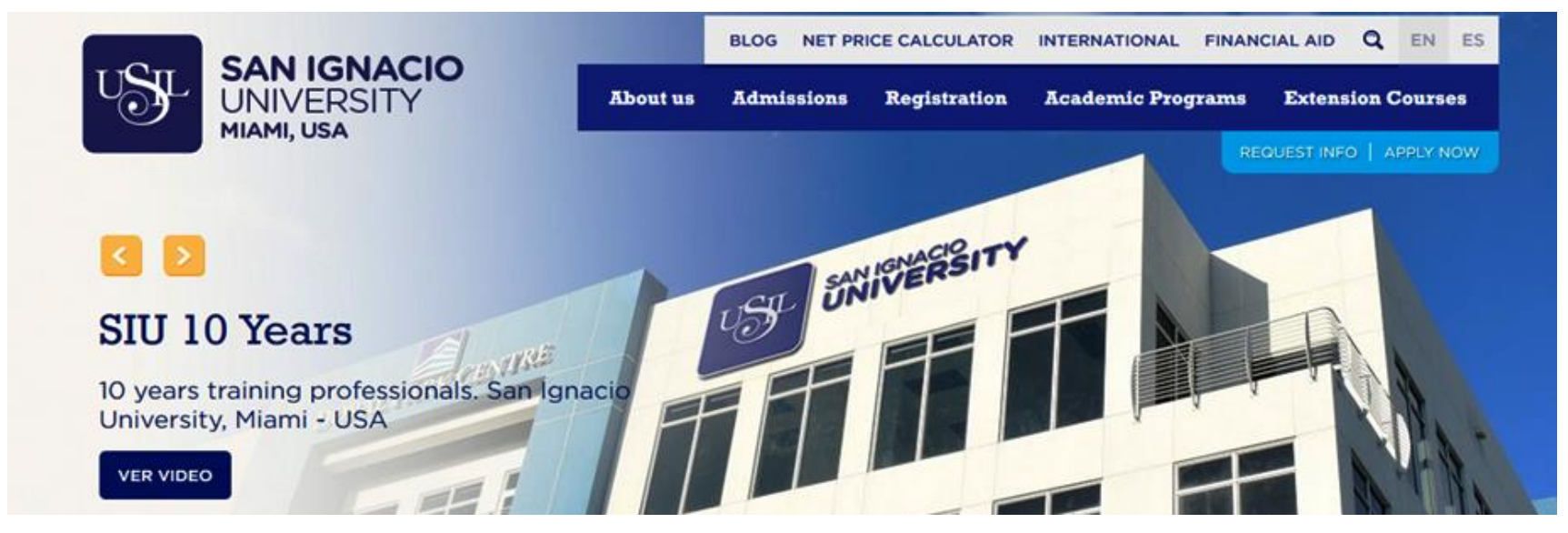

\title{
MOL2NET Flavonoid interaction with chitosan: planning 2017 active packing with antioxidant and antimicrobial activity
}

\author{
Diolino Ricardo de Oliveira Neto ${ }^{1}$, Cleiton Ferreira Barbosa ${ }^{1}$, Pablo Henrique Delmondes ${ }^{1}$ * \\ ${ }^{1}$ Grupo de Pesquisa em Tecnologia Farmacêutica (TECFARM) das Faculdades Unidas do Vale do \\ Araguaia/UNIVAR - R. Moreira Cabral, 1000 - Setor Mariano, Barra do Garças - MT, 78600-000; \\ *Author to whom correspondence should be addressed; E-Mail: pablohdelmondes@ hotmail.com; \\ Tel.: +55-66-99238-6576.
}

\begin{abstract}
Active packaging is a packaging system that has incorporated additives and that interact directly with the food in order to prolong its quality and its useful life. Due to the bioindecomposability and toxicity of synthetic polymers and additives, the search for natural substances, which present more suitable characteristics for the production of active packages, such as chitosan, which is a naturally occurring polymer and flavonoids, increase, because they have low toxicity and activities antioxidant and antimicrobial. The purpose of this study to perform the interaction of flavonoids quercetin, rutin, quercitrin and artemetin with chitosan by molecular docking, aiming at the planning of new biodegradable and non-toxic active films. The molecular docking study was performed using Autodock 4.0. The three-dimensional structure of the chitosan was obtained through the PolySac3DB bank, while the flavonoid structures were acquired through PubChem. The results showed that the flavonoids quercetin, quercitrin and artemetin interacted attractively with chitosan. Quercetin was the flavonoid that interacted more stable, with an energy expenditure of -3.61 $\mathrm{kcal} / \mathrm{mol}$. The rutin was the only flavonoid, among those involved in the study, that did not interact attractively with chitosan, as its binding energy was $0.49 \mathrm{kcal} / \mathrm{mol}$. It is observed that the interaction of rutin with chitosan is impaired due to its high level of torsion. It was observed that the flavonoids targets of this study, with the exception of rutin, interacted attractively with chitosan, suggesting that they are good candidates for additives for the production of active films.
\end{abstract}

Keywords: chitosan, flavonoid, molecular docking, active packaging 


\section{Introduction:}

Active packaging is a packaging system that has built-in additives that will interact directly with the packaged food in order to prolong its quality and shelf life [1-2]. The packaging must support the microbiological and sensory competence of the food, in a way that contributes to the preservation of the quality of the packaged product, from its biological activities [3]. Recent studies have presented promising results regarding the use of flavonoids as additives in active packaging [4].

Flavonoids are compounds found in fruits and vegetables, responsible for the vibrant colors that attract pollinating insects and filter the ultraviolet rays of the sun. Flavonoids attracted interest from the scientific community, due to its diverse biological activities, such as antimicrobial, anti-inflammatory, antithrombotic and antioxidant activity, among others [5-6]. Flavonoids are compounds that belong to a certain class of natural compounds currently classified as micronutrients [7].

Chitosan is a naturally occurring polymer derived from the deacetylation process of chitin, and besides being considered the second most abundant polysaccharide in nature, it also has numerous technological and biological characteristics, finding applications in a variety of fields, , in the development of active films due to their favorable characteristics, such as biodegradability, biocompatibility, gel formation and bioactivity [8-10].

Molecular modeling techniques have been widely used in development studies of new active materials [11]. Molecular docking, specifically, can be used to predict the interaction of ligands with polymers [12]. Molecular docking is a fundamental tool to seek a better adjustment orientation of a ligand in a protein, in advance, that is, method of finding the best fit of two molecules [13-14].

Based on the characteristics of chitosan and the biological properties of flavonoids, the present study sought to investigate in silico, by molecular docking, the interaction of flavonoids quercetin, quercitrin, artemetin and rutin with the polymer, aiming at a better understanding of the mechanistic behavior of compounds in interaction with chitosan (flavonoid-polymer), in order to corroborate with experimental data widely described in the literature.

\section{Materials and Methods:}

The molecular docking study was performed through Autodock 4.0 [15]. The threedimensional structure of chitosan with 12-mers (Figure 1) was obtained through the PolySac3DB bank, while the flavonoid structures (Figure 2) were acquired through the PubChem molecule bank. For orientation of the ligands, a grid was positioned around the entire molecule with dimensions of $58 \AA$ on the $\mathrm{X}$ - axis, $126 \AA$ on the Y-axis and $56 \AA$ on the $\mathrm{Z}$ - axis. For the searches the Lamarckian Genetic Algorithm [1618] was used in 100 runs.bThe initial population was defined as 150 and the search process occurred through random initial conformations. The maximum value of energy assessments chosen was 25,000,000, while the maximum number of generations was maintained at 27,000, as well as the number of elitism was maintained at 1 . The rates of genetic mutation and crossover were respectively 0.02 and 0,80 . After completing the calculations, 100 different conformations were obtained and grouped into different clusters, defined by energy proximity and RMS values, according to the AutoDock default [15]. 


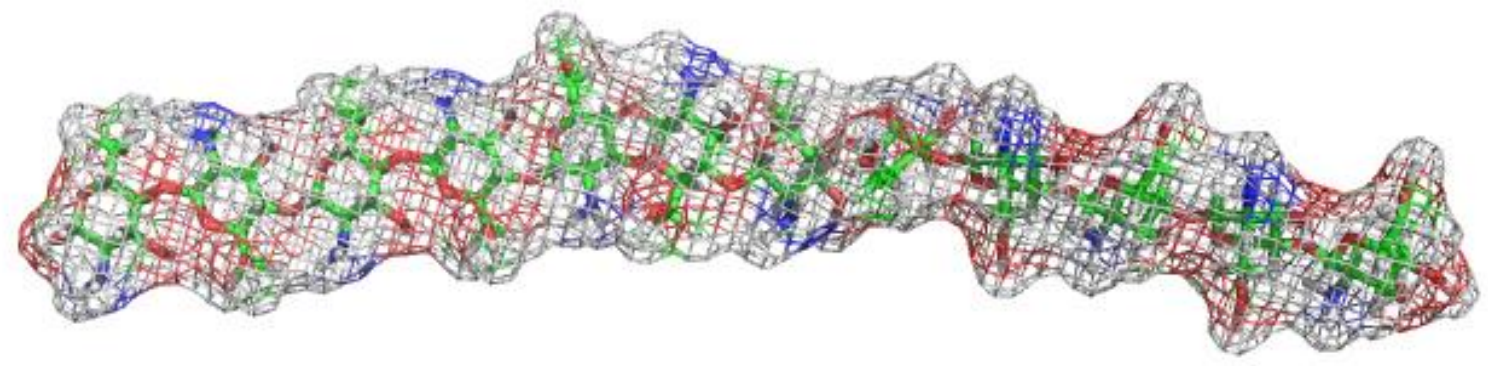

Figure 1. Three-dimensional molecular structure of chitosan with 12 mers

a)

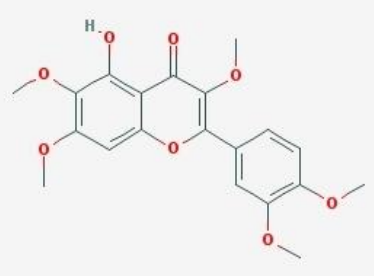

c)

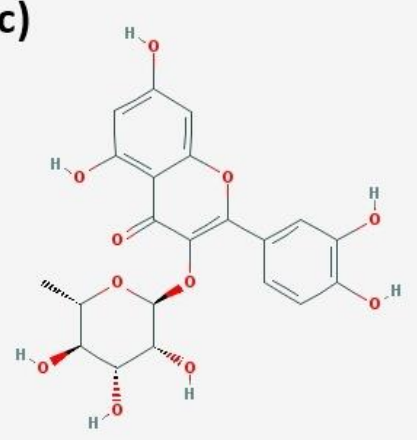

b)

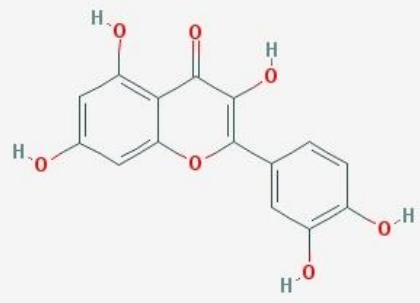

d)

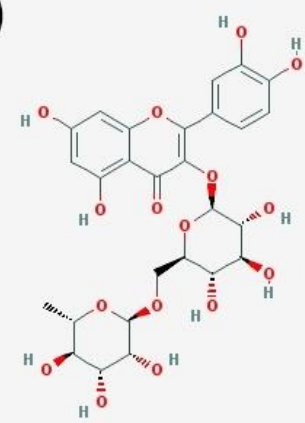

Figure 2. Two-dimensional structure of the flavonoids involved in the study. a) artemetin; b) quercetin; c) quercitrin; and d) rutin

\section{Results and discussion:}

The results showed that the flavonoids quercetin, quercitrin and artemetin interacted attractively with chitosan, as shown in Figure 3 and Table 1. Quercetin was the flavonoid that interacted more stable with an energy expenditure of $-3,61 \mathrm{kcal} / \mathrm{mol}$. The rutin was the only flavonoid, among those involved in the study, that did not interact attractively with chitosan, as its binding energy was $0.49 \mathrm{kcal} /$ mol. It is observed that the interaction of rutin with chitosan is impaired due to its high torsion level (Table 1).

In addition to the van der waals interactions formed between the flavonoid ring groups and the chitosan ring groups, several hydrogen bonds are formed between the polar groups of flavonoids with polar groups of chitosan.

The present study is similar to other experimental studies developed, where flavonoid quercetin was used as an additive and incorporated into chitosan efficiently [19-21]. 

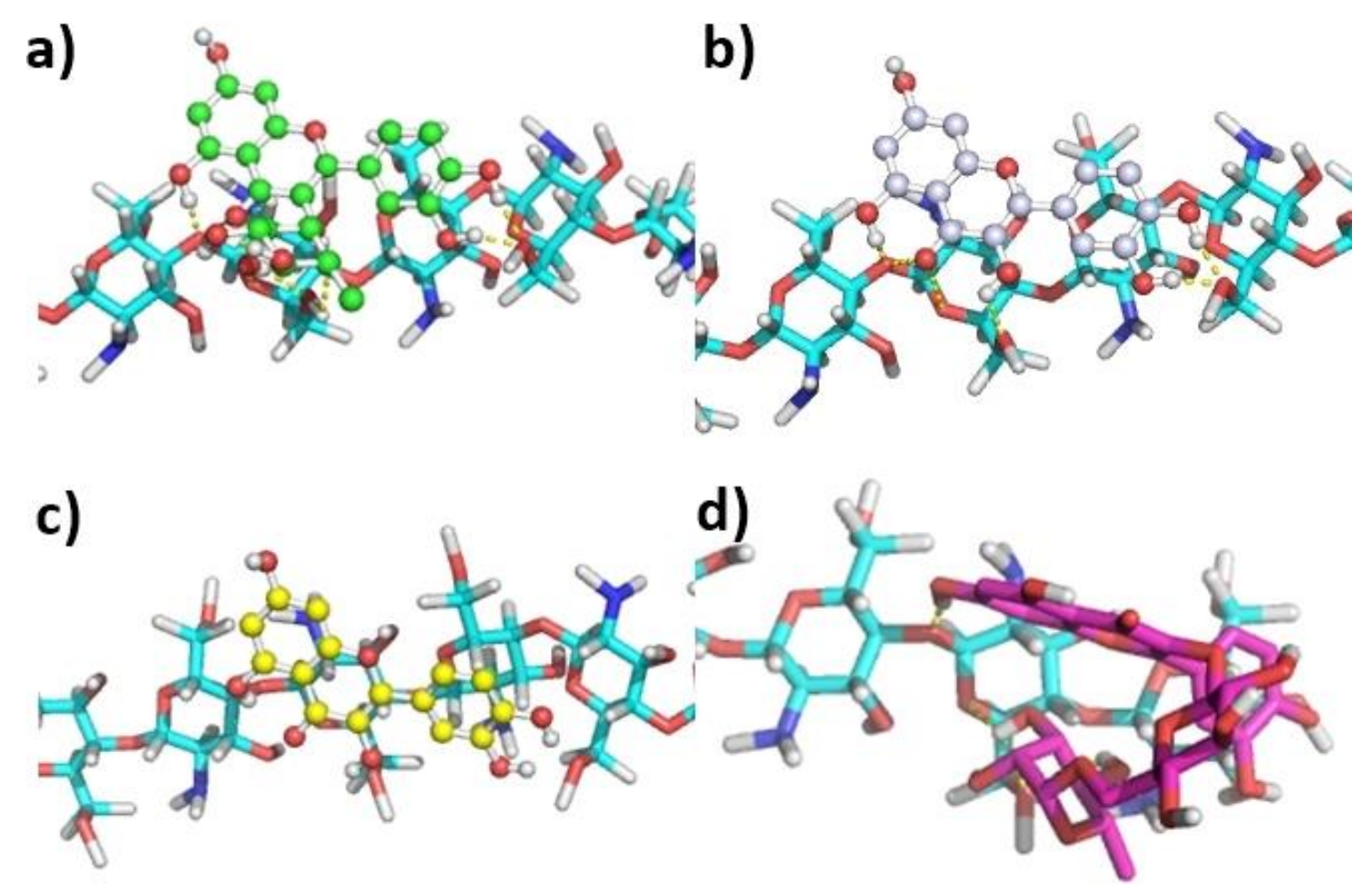

Figure 3. Interaction of ligands with chitosan. a) quercitrin; b) artemetin; c) Quercetin; d) Rutin

Table 1. Values obtained by molecular docking

\begin{tabular}{ccccc}
\hline Complex & $\begin{array}{c}\text { Free energy } \\
\text { docking } \\
(\mathbf{k c a l} / \mathbf{m o l})\end{array}$ & $\begin{array}{c}\text { Electrostatic } \\
\text { interaction } \\
\text { energy } \\
\mathbf{( k c a l / m o l )}\end{array}$ & $\begin{array}{c}\text { Van der Waals } \\
\text { interaction and } \\
\text { hydrogen } \\
\text { bonding energy } \\
\text { (kcal/mol) }\end{array}$ & $\begin{array}{c}\text { Torsional } \\
\text { Energy } \\
\text { (kcal/mol) }\end{array}$ \\
\hline $\begin{array}{c}\text { chitosan }+ \\
\text { Quercetin }\end{array}$ & -3.61 & -0.34 & -5.05 & 1.79 \\
$\begin{array}{c}\text { Chitosan }+ \\
\text { Quercitrin }\end{array}$ & -2.25 & -0.31 & -4.92 & 2.98 \\
$\begin{array}{c}\text { Chitosan }+ \\
\text { Rutin }\end{array}$ & 0.49 & -0.42 & -3.86 & 4.77 \\
$\begin{array}{c}\text { Chitosan }+ \\
\text { Artemetin }\end{array}$ & -2.52 & -0.34 & -4.27 & 2.09 \\
\hline
\end{tabular}

\section{Conclusion}

It was observed that the flavonoids targets of this study, with the exception of rutin, interacted attractively with chitosan, suggesting that they are good candidates for additives for the production of active films. 


\section{Conflicts of Interest:}

The authors declare no conflict of interest

\section{References}

1. Suppakul, P., Miltz, J. M., Sonneveld, K., \& Bigger, S. W. (2003). Active packaging technologies with an emphasis on antimicrobial packaging and its applications. Journal of Food Science, 68, 408-420.

2. Yingyuad, S., Ruamsin, S., Leekprokok, T., Douglas, S., Pongamphai, S., \& Siripatrawan, U. (2006). Effect of chitosan coating and vacuum packaging on the quality of refrigerated grilled pork. Packaging Technology and Science, 19, 149-157.

3. Santos, A. F. (2014). Produção de filmes ativos a base de amido e zeólita modificada com prata. 44F. Trabalho de conclusão de curso Tecnologia em Alimentos, Universidade Tecnológica Federal do Paraná. Campo Mourão, 2014.

4. Mar C. L., María, J. M. L.V. (2014)

"Analytical determination of flavonoids aimed to analysis of natural samples and active packaging applications." Food chemistry 150, 119-127.

5. Kumar, Shashank, and Abhay K. Pandey (2013). "Chemistry and biological activities of flavonoids: an overview." The Scientific World Journal 2013.

6. Nakabayashi, Ryo, et al. (2014) "Enhancement of oxidative and drought tolerance in

Arabidopsis by overaccumulation of antioxidant flavonoids." The Plant Journal 77, 3, 367-379.

7. Alves, C. Q., et al. (2007). Avaliação da atividade antioxidante de flavonoides. Diálogo $e$ Ciência-Revista da rede de ensino FTC. 5, 12.

8. Santana, M. C. C. B., et al. (2012) Incorporação de urucum como aditivo antioxidante em embalagens biodegradáveis a base de quitosana. Ciência rural, Santa Maria.
9. Cerqueira, T. et al. (2011). Recobrimento de goiabas com filmes proteicos e de quitosana, Bragantia, 70, 1, 216-221.

10. Siripatrawan, U., Bruce R. H. (2010).

"Physical properties and antioxidant activity of an active film from chitosan incorporated with green tea extract." Food Hydrocolloids. 24, 8, 770-775.

11. Samanta, S., Roccatano, D. (2013). Interaction of curcumin with PEO-PPO-PEO block copolymers: a molecular dynamics study. The Journal of Physical Chemistry B, 117, 11, 3250-3257.

12. Sanyakamdhorn, S., Agudelo, D., Tajmirriahi, H. A. (2013). Encapsulation of antitumor drug doxorubicin and its analogue by chitosan nanoparticles. Biomacromolecules, 14, 2, 557563.

13. Meng, X. et al. (2011). Molecular Docking: A powerful approach for structure-based drug discovery, Current Computer-Aided Drug Desing. 7: 146-157.

14. Delmondes, P. H. (2016) Estudo Computacional da solubilidade de ácidos fenólicos naturais e suas interações com a quitosana. 2016. 73f. Dissertação (Mestrado em Ciência de Materiais) - Universidade Federal de Mato Grosso, Campus Universitário do Araguaia, Barra do Garças.

15. Morris, G. M. et al. (2009) AutoDock4 and AutoDockTools4: Automated docking with selective receptor flexibility. Journal of computational chemistry, 30, 2785-2791.

16. Mashhadi, H. R.; Shanechi, H. M.; Lucas, C. (2003) A new genetic algorithm with Lamarckian individual learning for generation scheduling. IEEE Transactions on Power Systems, 18, 1181-1186.

17. Thomsen, R. (2003) Flexible ligand docking using evolutionary algorithms: investigating the effects of variation operators and local search hybrids. Biosystems, 72, 57-73. 
18. Thormann, M.; Poins, M. Massive (2001) docking of flexible ligands using environmental niches in parallelized genetic algorithms. J.

Comput. Chem., 22, 1971-1982.

19. Torres, E., Marín, V., Aburto, J., Beltrán, H. I., Shirai, K., Villanueva, S., \& Sandoval, G. (2012). Enzymatic modification of chitosan with quercetin and its application as antioxidant edible films. Applied biochemistry and microbiology, 48, (2), 151-158.

20. Božič, M., Gorgieva, S., \& Kokol, V. (2012). Homogeneous and heterogeneous methods for laccase-mediated functionalization of chitosan by tannic acid and quercetin. Carbohydrate polymers, 89(3), 854-864.

21. Souza, M. P., Vaz, A. F., Silva, H. D., Cerqueira, M. A., Vicente, A. A., \& Carneiro-daCunha, M. G. (2015). Development and characterization of an active chitosan-based film containing quercetin. Food and Bioprocess Technology, 8(11), 2183-2191. 